\title{
Alprazolam-induced dose-dependent anorgasmia: case analysis
}

Kenneth R. Kaufman, Melissa Coluccio, Michelle Linke, Elizabeth Noonan, Ronke Babalola and Rehan Aziz

\section{Background}

Sexual dysfunctions are associated with multiple medical and psychiatric disorders, as well as pharmacotherapies used to treat these disorders. Although sexual dysfunctions negatively affect both quality of life and treatment adherence, patients infrequently volunteer these symptoms and clinicians do not pose directed questions to determine their presence or severity. This issue is especially important in psychiatric patients, for whom most common psychotropics may cause sexual dysfunctions (antidepressants, antipsychotics, anxiolytics and mood-stabilising agents). There is limited literature addressing benzodiazepines, and alprazolam in particular.

\section{Aims}

To report dose-dependent alprazolam anorgasmia.

\section{Method}

Case analysis with PubMed literature review.

\section{Results}

A 30-year-old male psychiatric patient presented with new-onset anorgasmia in the context of asymptomatic generalised anxiety disorder, social anxiety, panic disorder with agoraphobia, obsessive-compulsive disorder, major depression in remission, and attention-deficit hyperactivity disorder treated with escitaIopram $10 \mathrm{mg}$ q.a.m., gabapentin $1000 \mathrm{mg}$ total daily dose, lisdexamfetamine dimesylate $70 \mathrm{mg}$ q.a.m., nortriptyline $60 \mathrm{mg}$ q.h.s. and alprazolam extended-release $2.5 \mathrm{mg}$ total daily dose All psychotropic doses had been constant for $>6$ months excluding alprazolam, which was titrated from $1 \mathrm{mg}$ to $2.5 \mathrm{mg}$ total daily dose. The patient denied any sexual dysfunction with alprazolam at $1 \mathrm{mg}$ q.d. and $1 \mathrm{mg}$ b.i.d. Within 1 week of increasing alprazolam to $2.5 \mathrm{mg}$ total daily dose, the patient reported anorgasmia. Anorgasmia was alprazolam dosedependent, as anorgasmia resolved with reduced weekend dosing (1 mg b.i.d. Saturday/1.5 mg total daily dose Sunday).

\section{Conclusions}

Sexual dysfunction is an important adverse effect negatively influencing therapeutic outcome. This case reports alprazolaminduced dose-dependent anorgasmia. Clinicians/patients should be aware of this adverse effect. Routine sexual histories are indicated.

\section{Declaration of interest}

None.

\section{Keywords}

Alprazolam; benzodiazepine; sexual dysfunction; anorgasmia; adverse effect; nonadherence; anxiety disorder, major depressive disorder; obsessive-compulsive disorder, attention-deficit hyperactivity disorder; clinical care; education.

\section{Copyright and usage}

(C) The Royal College of Psychiatrists 2018. This is an Open Access article, distributed under the terms of the Creative Commons Attribution-NonCommercial-NoDerivatives licence (http://creativecommons.org/licenses/by-nc-nd/4.0/), which permits noncommercial re-use, distribution, and reproduction in any medium, provided the original work is unaltered and is properly cited. The written permission of Cambridge University Press must be obtained for commercial re-use or in order to create a derivative work
Sexual dysfunctions are associated with multiple medical and psychiatric disorders, as well as pharmacotherapies used to treat these disorders. ${ }^{1,2}$ Although sexual dysfunctions negatively affect both quality of life (QoL) and treatment adherence, patients infrequently volunteer these symptoms and clinicians often do not pose directed questions to determine their presence or severity. ${ }^{2-5}$ Further, patients may not share their nonadherence, resulting in both symptomatic regression and potentially inappropriate medical and/or psychiatric care. This issue is especially important in psychiatric patients, for whom most common psychotropics may cause sexual dysfunctions (antidepressants, antipsychotics, anxiolytics and mood-stabilising agents). ${ }^{6-8}$

Sexual dysfunction adverse effects, including delayed orgasmic activity, have been reported with different benzodiazepines with varying frequency and selectivity. ${ }^{8-11}$ The limited literature addressing alprazolam and these adverse effects, anorgasmia in particular, is inconsistent, which may be secondary to methodology and sample size. The Lydiard study was an open, uncontrolled small survey $(N=32)$ without a standardised scale that reported $50 \%$ of patients with decreased orgasmic activity. ${ }^{11}$ The O'Sullivan study, presenting safety and side-effect data associated with a randomised placebo-controlled efficacy trial of alprazolam (mean total daily dose $5 \mathrm{mg}$ ) in the treatment of panic disorder with agoraphobia, reported that $25 \%$ of patients in the alprazolam treatment arm
$(N=77)$ noted sexual dysfunction ('decreased libido and delay in or failure to reach orgasm'). ${ }^{12}$ The recent Márquez study, comparing the efficacy of alprazolam in two different formulations in the treatment of acute phase panic disorders $(N=190)$, utilised the standardised Arizona Sexual Experience Scale (ASEX) and noted that the 60-day treatment ASEX scores were non-significantly lower than baseline, concluding that alprazolam 'did not affect the patients in their sexual sphere. ${ }^{13,14}$

To better appreciate the importance of anorgasmia with alprazolam, its role in treatment nonadherence and patient-oriented dosing strategies, this case report describes alprazolam-induced dose-dependent anorgasmia.

\section{Method}

Case analysis with PubMed literature review.

\section{Results}

A 30-year-old male psychiatric patient presented with new-onset anorgasmia in the context of asymptomatic generalised anxiety disorder, social anxiety, panic disorder with agoraphobia, obsessive- 
compulsive disorder, major depression in remission, and attentiondeficit hyperactivity disorder treated with escitalopram $10 \mathrm{mg}$ q.a.m., gabapentin $1000 \mathrm{mg}$ total daily dose, lisdexamfetamine dimesylate $70 \mathrm{mg}$ q.a.m., nortriptyline $60 \mathrm{mg}$ q.h.s. and alprazolam extended release (ER) $2.5 \mathrm{mg}$ total daily dose ( $1 \mathrm{mg}-0.5 \mathrm{mg}-1 \mathrm{mg}$ ). Medical conditions included elevated transaminases, obesity (body mass index $31.86 \mathrm{~kg} / \mathrm{m}^{2}$ ), dyslipidaemia and gastroesophageal reflux disorder (GERD). All standard blood chemistries (comprehensive metabolic panel, complete blood count, thyroid stimulating hormone and lipid panel) were normal, excluding elevated transaminases (aspartate aminotransferase (AST) $43 \mathrm{U} / \mathrm{L}$ and alanine aminotransferase (ALT) $87 \mathrm{U} / \mathrm{L}$ ), elevated triglycerides (202 mg/ $\mathrm{dL})$ and decreased high-density lipoprotein $(35 \mathrm{mg} / \mathrm{dL})$. His nortriptyline blood level was $68 \mathrm{mcg} / \mathrm{mL}$. A right upper quadrant abdominal ultrasound revealed fatty liver changes. His medical conditions were stable during the time period of alprazolam titrations.

All psychotropic doses had been constant for $>6$ months, excluding alprazolam ER, which was titrated from $1 \mathrm{mg}$ to $2.5 \mathrm{mg}$ total daily dose for recently increased anxiety that resolved on the higher daily dose. The patient denied any sexual dysfunction with alprazolam ER at $1 \mathrm{mg}$ q.d. and $1 \mathrm{mg}$ b.i.d.. Within 1 week of increasing alprazolam ER to $2.5 \mathrm{mg}$ total daily dose, the patient reported anorgasmia. Anorgasmia was alprazolam dose-dependent, as anorgasmia resolved with reduced weekend dosing (1 mg b.i.d. Saturday; $1.5 \mathrm{mg}$ total daily dose Sunday). During a 10-week period, the patient had repetitively reduced weekend alprazolam, creating an on/off/on/off dose-dependent adverse effect response pattern. He reviewed all aspects of sexual functioning and recognised that at alprazolam ER $1.5 \mathrm{mg}$ total daily dose (Sundays) there was no sexual dysfunction, at $1 \mathrm{mg}$ b.i.d. there was limited delayed orgasmic activity (Saturdays), and at $2.5 \mathrm{mg}$ total daily dose (weekdays) there was anorgasmia. Further, following the 10week period described, the patient experimented with taking weekday alprazolam ER 2-2.5 mg q.a.m. only and noted significantly improved orgasmic activity in the evening, suggesting that beyond being dose dependent, this adverse effect is concentration dependent.

\section{Discussion}

This unique case presents important steps in determining the aetiology of this patient's sexual dysfunction (decreased orgasmic activity and subsequent anorgasmia) in the context of multiple psychiatric diagnoses, medical comorbidities and psychotropic interventions. ${ }^{3}$ By addressing each step with the addition of a timeline describing the development and/or improvement in the sexual dysfunction, the probability of alprazolam-induced anorgasmia could be scored as doubtful, possible, probable or definite by the Naranjo Scale for adverse drug effects. ${ }^{15}$

First, each of the patient's psychiatric diagnoses were associated with sexual dysfunctions - major depressive disorder, obsessivecompulsive disorder, generalised anxiety disorder, social anxiety, panic disorder and attention-deficit hyperactivity disorder. ${ }^{1,16-20}$ Of note, reported findings may have been influenced by concurrent treatment with pharmacotherapies and/or associated comorbidities. Second, both GERD and obesity are associated with increased sexual dysfunction. ${ }^{1,21,22}$ Third, escitalopram, gabapentin, nortriptyline and alprazolam have each been associated with increased sexual dysfunction. ${ }^{6,8,11,12,23-25}$ Thus, multiple factors (psychiatric/ medical comorbidities and various psychotropics), individually and/or in various combinations, may be the aetiological basis for one or more sexual dysfunctions. Fourth, the patient described normal sexual function with stable medical and psychiatric diagnoses and baseline psychotropics. Fifth, when considering the onset of decreased orgasmic activity and anorgasmia, only two events had occurred - increased anxiety that had necessitated, and was responsive to, increased alprazolam. Sixth, the patient's relative weekend alprazolam nonadherence resulted in an on/off/on/off design compared with the standard weekday regimen, with sexual dysfunction (delayed orgasmic activity or anorgasmia) mirroring the alprazolam total daily dose which was repeated over a 10 -week time period. Seventh, the patient's further experimentation with morning weekday dosing only, as opposed to morning/midday/evening dosing, with diminished effect on the presumptive alprazolaminduced sexual dysfunction, suggested a concentration effect. ${ }^{26,27}$ Based on this stepwise analysis, alprazolam-induced anorgasmia was scored as probable by the Naranjo Scale. ${ }^{15}$

Alprazolam-induced anorgasmia has no well-defined mechanism of action in humans. Potential indirect and direct aetiologies include, but are not limited to, drug-drug pharmacokinetic interactions, pharmacodynamic synergism of prescribed medications/psychotropics on sexual dysfunctions, and effects of alprazolam on neurotransmitters. In the first instance, alprazolam is a substrate of cytochrome P450 3A4 (CYP3A4) and is not an inhibitor/ inducer of other cytochrome isoenzymes; as such, the presence of alprazolam in different dosages would not be expected to change the concentrations of other prescribed medications that might also cause sexual dysfunctions. In this case, only escitalopram was a (weak) CYP3A inhibitor; it has been suggested that at therapeutic dosage there should be no clinically significant effect on alprazolam. ${ }^{28}$ In the second instance, pharmacodynamic synergism could be considered a possible factor in the current and similar presentations - but determination of such would require medication withdrawal, which in this case was clinically neither feasible nor warranted in light of the dose-dependent alprazolam-induced anorgasmia which resolved with dose reduction. In the third instance, alprazolam, similar to other benzodiazepines, is a positive allosteric modulator of the gamma-amino butyric acid (GABA)-A receptor. ${ }^{29,30}$ GABA is the primary central nervous system inhibitory neurotransmitter, with high concentrations in the cortex and limbic system. ${ }^{30}$ Animal studies with GABA agonists, metabolic inhibitors, antagonists and synthesis inhibitors confirm the importance of GABA in sexual functioning - increased GABA activity is associated with decreased sexual behaviours, whereas decreased GABA activity is associated with increased sexual functioning. ${ }^{31,32}$ Hypothetically, anorgasmia could be secondary to GABA inhibition of dopamine, with resultant increased prolactin levels. ${ }^{33,34}$

Key strengths in this case report include that: (a) the patient's relative alprazolam nonadherence with an on/off/on/off design revealed a direct correlation between total daily dose of alprazolam and anorgasmia; (b) excluding the recent increase in anxiety and associated increased alprazolam, the patient had been stable for $>6$ months with no other documented changes in psychotropics; (c) although patients are frequently reluctant to reveal sexual dysfunction symptoms, this patient immediately identified anorgasmia as an important treatment problem, as it negatively affected his QoL; and (d) the clinician included both sexual dysfunction questions and a review of psychotropic adverse effects including sexual dysfunction in each session.

Limitations in this case report include that: (a) as a single case report $(N=1)$, the findings cannot be generalised; (b) as no alprazolam blood levels were obtained, the concentration-dependent effects of alprazolam could not be reported; (c) the patient's increased anxiety could be a confounding factor, as anxiety is associated with decreased sexual functioning; however, no rating scales (e.g. the Hospital Anxiety and Depression Scale (HADS) or the Hamilton Anxiety Rating Scale (HAM-A)) were used that might help elucidate this issue; (d) no pill counts were obtained, which might have suggested any additional psychotropic noncompliance 
that could affect the reported sexual dysfunction; (e) no psychometric sexual functioning scale (e.g. ASEX) was used; and (f) no hormone levels were obtained. Finally, for ethical reasons, the patient could not be requested to repeat the relative nonadherence with further testing to verify the current findings.

The potential clinical implications of this report can best be appreciated in the context of anxiety disorder prevalence and alprazolam prescription patterns. Specifically, the National Comorbidity Survey Replication (NCS-R) study, ${ }^{35}$ using retrospective ascertainment, reported that anxiety disorders have a $28.8 \%$ lifetime prevalence, while the Dunedin study, ${ }^{36}$ using prospective ascertainment as opposed to retrospective ascertainment in the NCS-R study, noted a lifetime anxiety disorder prevalence of $49.5 \%$ by age 32 . Alprazolam is the most frequently prescribed benzodiazepine and the third most frequently prescribed psychotropic in the USA (5.29 million individuals and approximately 25.7 million prescriptions in 2013). ${ }^{37}$ Since sexual dysfunctions are frequently not volunteered by patients nor queried by physicians, alprazolaminduced sexual dysfunction may be a very significant problem affecting QoL that remains underappreciated and inadequately addressed by healthcare professionals. To address this problem, large-scale studies are required, as are routine sexual histories, and further education for clinicians and patients.

\section{Conclusion}

Sexual dysfunction is an important psychosocial comorbidity affecting QoL and treatment adherence. This case described dosedependent alprazolam-induced anorgasmia in the context of multiple psychotropics, psychiatric diagnoses, and medical diagnoses. Routine sexual histories are necessary to ascertain the presence of sexual dysfunctions, avoid medicine nonadherence, and to maximise treatment outcomes. Further education regarding alprazolam-induced sexual dysfunction is indicated for both clinicians and patients.

Kenneth R. Kaufman, MD, FRCPsych, DLFAPA, FAES, Department of Psychiatry, Department of Neurology, and Department of Anesthesiology, Rutgers Robert Wood Johnson Medical School, USA; Melissa Coluccio, MD, Department of Psychiatry, Rutgers Robert Wood Johnson Medical School, USA; Michelle Linke, BA, MS.Ed, Department of Psychiatry, Rutgers Robert Wood Johnson Medical School, USA; Elizabeth Noonan Department of Psychology, School of Arts and Sciences, Rutgers University, USA; Ronke Babalola, MD, MPH, Department of Psychiatry, Rutgers Robert Wood Johnson Ronke Babalola, MD, MPH, Department of Psychiatry, Rutgers Robert Wood Johnson
Medical School, USA; Rehan Aziz, MD, FAPA, Department of Psychiatry and Department of Neurology, Rutgers Robert Wood Johnson Medical School, USA.

Correspondence: Kenneth R. Kaufman, Departments of Psychiatry, Neurology and Anesthesiology, Rutgers Robert Wood Johnson Medical School, 125 Paterson Street, Suite \#2200, New Brunswick, New Jersey 08901, USA

Email: kaufmakr@rwjms.rutgers.edu

First received 10 May 2018, final revision 22 May 2018, accepted 24 May 2018

\section{References}

1 McCabe MP, Sharlip ID, Lewis R, Atalla E, Balon R, Fisher AD, et al. Risk factors for sexual dysfunction among women and men: a consensus statement from the Fourth International Consultation on Sexual Medicine 2015. J Sex Med 2016; 13: 153-67.

2 Montejo AL, Montejo L, Baldwin DS. The impact of severe mental disorders and psychotropic medications on sexual health and its implications for clinical management. World Psychiatry 2018; 17: 3-11.

3 Kaufman KR, Coluccio M, Sivaraaman K, Campeas M. Lamotrigine-induced sexual dysfunction and noncompliance: case analysis with literature review. BJPsych Open 2017; 3: 249-53.
4 Kaufman KR, Wong S, Sivaraaman K, Anim C, Delatte D. Epilepsy and AEDinduced decreased libido - the unasked psychosocial comorbidity. Epilepsy Behav 2015; 52: 236-8.

5 Mitchell AJ, Selmes T. Why don't patients take their medicine? Reasons and solutions in psychiatry. Adv Psychiatri Treat 2007; 13: 336-46.

6 La Torre A, Giupponi G, Duffy D, Conca A. Sexual dysfunction related to psychotropic drugs: a critical review - part I: antidepressants. Pharmacopsychiatry 2013; 46: 191-9.

7 La Torre A, Conca A, Duffy D, Giupponi G, Pompili M, Grözinger M. Sexual dysfunction related to psychotropic drugs: a critical review part II: antipsychotics. Pharmacopsychiatry 2013; 46: 201-8.

8 La Torre A, Giupponi G, Duffy DM, Pompili M, Grözinger M, Kapfhammer HP, et al. Sexual dysfunction related to psychotropic drugs: a critical review. Part III: mood stabilizers and anxiolytic drugs. Pharmacopsychiatry 2014; 47: 1-6.

9 Fossey MD, Hamner MB. Clonazepam-related sexual dysfunction in male veterans with PTSD. Anxiety 1994-1995; 1: 233-6.

10 Shen WW, Sata LS. Inhibited female orgasm resulting from psychotropic drugs. A five-year, updated, clinical review. J Reprod Med 1990; 35: 11-4.

11 Lydiard RB, Howell EF, Laraia MT, Ballenger JC. Sexual side effects of alprazolam. Am J Psychiatry 1987; 144: 254-5.

12 O'Sullivan GH, Noshirvani H, Başoğlu M, Marks IM, Swinson R, Kuch K, et al. Safety and side-effects of alprazolam. Controlled study in agoraphobia with panic disorder. Br J Psychiatry 1994; 165: 79-86.

13 Márquez $\mathrm{M}$, Arenoso $\mathrm{H}$, Caruso N. Efficacy of alprazolam sublingual tablets in the treatment of the acute phase of panic disorders. Actas Esp Psiquiatr 2011; 39: 88-94.

14 McGahuey CA, Gelenberg AJ, Laukes CA, Moreno FA, Delgado PL, McKnight KM, et al. The Arizona Sexual Experience Scale (ASEX): reliability and validity. J Sex Marital Ther 2000; 26: 25-40.

15 Naranjo CA, Shear NH, Lanctôt KL. Advances in the diagnosis of adverse drug reactions. J Clin Pharmacol 1992; 32: 897-904.

16 Kendurkar A, Kaur B. Major depressive disorder, obsessive-compulsive disorder, and generalized anxiety disorder: do the sexual dysfunctions differ? Prim Care Companion J Clin Psychiatry 2008; 10: 299-305.

17 Bodinger L, Hermesh H, Aizenberg D, Valevski A, Marom S, Shiloh R, et al. Sexual function and behavior in social phobia. J Clin Psychiatry 2002; 63: 874-9.

18 Aksoy UM, Aksoy SG, Maner F, Gokalp P, Yanik M. Sexual dysfunction in obsessive compulsive disorder and panic disorder. Psychiatr Danub 2012; 24: 381-5.

19 Blumentals WA, Gomez-Caminero A, Brown RR, Vannappagari V, Russo LJ. A case control study of erectile dysfunction among men with panic disorder. Int J Impot Res 2004; 16: 299-302.

20 Bijlenga D, Vroege JA, Stammen AJM, Breuk M, Boonstra AM, van der Rhee K, et al. Prevalence of sexual dysfunctions and other sexual disorders in adults with attention-deficit/hyperactivity disorder compared to the general population. Atten Defic Hyperact Disord. 2018; 10: 87-96.

21 Iovino $P$, Pascariello A, Limongelli $P$, Tremolaterra F, Consalvo D, Sabbatini F, et al. The prevalence of sexual behavior disorders in patients with treated and untreated gastroesophageal reflux disease. Surg Endosc 2007; 21: 1104-10

22 Katz A. Obesity and sexual dysfunction: making the connection. Am J Nurs 2017; 117: 45-50.

23 Serretti A, Chiesa A. Treatment-emergent sexual dysfunction related to antidepressants: a meta-analysis. J Clin Psychopharmacol 2009; 29: 259-66.

24 Strohmaier J, Wüst S, Uher R, Henigsberg N, Mors O, Hauser J, et al. Sexual dysfunction during treatment with serotonergic and noradrenergic antidepressants: clinical description and the role of the 5-HTTLPR. World J Bio Psychiatry 2011; 12: 528-38

25 Kaufman KR, Struck PJ. Gabapentin-induced sexual dysfunction. Epilepsy Behav 2011; 21: 324-6.

26 Wright CE. Clinical pharmacokinetics of alprazolam extended release: a summary. Curr Therap Res 1995; 56: 947-56.

27 Glue P, Fang A, Gandelman K, Klee B. Pharmacokinetics of an extended release formulation of alprazolam (Xanax XR) in healthy normal adolescent and adult volunteers. Am J Ther 2006; 13: 418-22.

28 Hall J, Naranjo CA, Sproule BA, Herrmann N. Pharmacokinetic and pharmacodynamic evaluation of the inhibition of alprazolam by citalopram and fluoxetine. J Clin Psychopharmacol 2003; 23: 349-57.

29 Goodchild CS. GABA receptors and benzodiazepines. Br J Anaesth 1993; 71 : 127-33. 
30 Griffin 3rd CE, Kaye AM, Bueno FR, Kaye AD. Benzodiazepine pharmacology and central nervous system-mediated effects. Ochsner J. 2013; 13: 214-23.

31 Fernández-Guasti A, Larsson K, Beyer C. GABAergic control of masculine sexual behavior. Pharmacol Biochem Behav 1986; 24: 1065-70.

32 Rodríguez-Manzo G, Canseco-Alba A. A new role for GABAergic transmission in the control of male rat sexual behavior expression. Behav Brain Res 2017; 320: 21-9.

33 Lee TY, Pan JT. Involvement of central GABAergic neurons in basal and diurnal changes of tuberoinfundibular dopaminergic neuronal activity and prolactin secretion. Life Sci 2001; 68: 1965-75.

34 Hollander AB, Pastuszak AW, Hsieh TC, Johnson WG, Scovell JM, Mai CK, et al. Cabergoline in the treatment of male orgasmic disorder - a retrospective pilot analysis. Sex Med 2016; 4: e28-33.
35 Kessler RC, Berglund P, Demler O, Jin R, Merikangas KR, Walters EE. Lifetime prevalence and age-of-onset distributions of DSM-IV disorders in the National Comorbidity Survey Replication. Arch Gen Psychiatry 2005; 62: 593-602.

36 Moffitt TE, Caspi A, Taylor A, Kokaua J, Milne BJ, Polanczyk G, et al. How common are common mental disorders? Evidence that lifetime prevalence rates are doubled by prospective versus retrospective ascertainment. Psychol Med 2010; 40: 899-909.

37 Moore TJ, Mattison DR. Adult utilization of psychiatric drugs and differences by sex, age, and race. JAMA Intern Med 2017; 177: 274-5. 